\title{
Artificial humidification for the mechanically ventilated patient
}

Selvaraj N (2010) Artificial humidification for the mechanically ventilated patient. Nursing Standard. 25, 8, 41-46. Date of acceptance: March 252010.

\section{Summary}

Caring for patients who are mechanically ventilated poses many challenges for critical care nurses. It is important to humidify the patient's airways artificially to prevent complications such as ventilator-associated pneumonia. There is no gold standard to determine which type of humidification is best for patients who are artificially ventilated. This article provides an overview of commonly used artificial humidification for mechanically ventilated patients and discusses nurses' responsibilities in caring for patients receiving artificial humidification.

\section{Author}

Nelson Selvaraj, charge nurse, Critical Care Unit, Manchester Royal Infirmary, Manchester. Email: nelson.selvaraj@cmft.nhs.uk

\section{Keywords}

\section{Artificial humidification, mechanical ventilation, respiratory care, tracheostomy tube}

These keywords are based on subject headings from the British Nursing Index. All articles are subject to external double-blind peer review and checked for plagiarism using automated software. For author and research article guidelines visit the Nursing Standard home page at www.nursing-standard.co.uk. For related articles visit our online archive and search using the keywords.

\section{MECHANICAL VENTILATION USING} artificial airways such as endotracheal and tracheostomy tubes has many complications (Morán et al 2006). Appropriate humidification of inspired air is one of the components of the high impact interventions for mechanically ventilated patients (Department of Health (DH) 2007). High impact interventions are part of the care bundle approach that aims to prevent ventilator-associated pneumonia (National Institute for Health and Clinical Excellence (NICE) 2008). Although the provision of heat and humidity for the airways of mechanically ventilated patients is standard practice worldwide, there is considerable confusion among healthcare professionals on what constitutes optimal humidity and how to provide it (Ricard 2007). This article aims to provide readers with an understanding of why artificial humidification is important for mechanically ventilated patients and to help them select the most appropriate method of humidification for patients in their care. It also explores two common methods of artificial humidification: heated humidification and humidification via heat and moisture exchangers.

\section{Heat and moisture exchange}

The upper respiratory tract, primarily the nasopharynx, contains a large area of highly vascular, moist, mucous membrane. When air passes through the nasopharynx, it is warmed and humidified on inspiration, and the majority of the heat and moisture on expiration is reclaimed by the nasopharyngeal mucosa; this provides humidification to the rest of the respiratory tract on subsequent inspirations (Lorente et al 2006).

The gas that reaches the alveolar level is usually $100 \%$ saturated at body temperature, even if inspired air is at extremes of temperature or humidity. The point at which gases reach alveolar conditions is known as the isothermic boundary (Lemin 2009).

Under normal circumstances, the upper airways contribute effectively to heating and humidifying inspired air. However, this process is compromised when the upper airways are bypassed with an artificial airway, such as an endotracheal or tracheostomy tube. In this case the isothermic saturation boundary becomes located further down the respiratory tract with the delivery of cold medical gases during artificial ventilation (Lemin 2009). This results in severe heat and moisture loss from the respiratory mucosa (Ryan et al 2002) and impaired mucocilliary clearance - the ability of cilia to clear respiratory secretions - which causes pooling of mucus in the lower airways. Pools of mucus provide an ideal environment for bacterial colonisation, which predisposes the patient to infections such as ventilator-associated pneumonia (Chastre and Fagon 2002). Inadequate heat and humidification may also result in dried secretions and cause atelectasis. Atelectasis can ultimately lead to a decreased functional residual capacity 
(the volume of gas in the lungs at the end of normal exhalation) and poor lung compliance, which can severely impair gas exchange (Poolacherla and Nickells 2006). Artificial humidification is therefore an essential aspect of caring for mechanically ventilated patients.

\section{Optimal humidity}

Humidity (the level of water vapour in air) can be expressed as absolute humidity or relative humidity (Ryan et al 2002). Absolute humidity is the amount of water vapour present in a gas, which is usually expressed as $\mathrm{mgH}_{2} \mathrm{O} / \mathrm{L}$.

Absolute humidity increases with increasing gas temperature and decreases with decreasing gas temperature (Branson 2007). For example, at a room temperature of $20^{\circ} \mathrm{C}$, the absolute humidity of gas is $17 \mathrm{mgH}_{2} \mathrm{O} / \mathrm{L}$ and by the time gas reaches the lungs it will have been warmed to $37^{\circ} \mathrm{C}$ and contain $44 \mathrm{mgH}_{2} \mathrm{O} / \mathrm{L}$ absolute humidity (Lorente et al 2006).

Relative humidity is normally expressed as a percentage. The relative humidity of a gas saturated with water vapour at any temperature is $100 \%$ and this percentage will fall as the gas temperature rises (Lorente et al 2006). Relative humidity measures how much water vapour a gas is holding compared with how much it could hold at that temperature (Branson 2007). An inspired gas that is conditioned to core body temperature $\left(37^{\circ} \mathrm{C}\right)$ and has $100 \%$ relative humidity is important for an optimal clearance of mucus from the respiratory tract (Ryan et al 2002).

After passing through the nasopharynx, the temperature of inspired gas at the carina (the point at which the trachea bifurcates into the right and left bronchi) is $34-37^{\circ} \mathrm{C}$, achieving an absolute humidity of $42-44 \mathrm{mgH}_{2} \mathrm{O} / \mathrm{L}$ and a relative humidity of $100 \%$. This is the optimum humidity for effective mucocilliary system function (Lorente et al 2006).

\section{Ventilator care bundle}

High impact interventions are evidence-based tools. They incorporate care bundles that aim to prevent healthcare-associated infections and reduce the risk of infection to patients by encouraging healthcare staff to comply with evidence-based practice and guidelines every time they undertake a clinical procedure (DH 2007).

A care bundle is a group of evidence-based interventions applied to the management of a particular condition (DH 2007). When these interventions are grouped together in a single protocol this should improve clinical outcomes (Fulbrook and Mooney 2003). The ventilator care bundle comprises a group of interventions that aim to prevent the development of ventilator-associated pneumonia (Box 1) (DH2007).

No direct relationship has yet been established between inadequate humidification and the occurrence of ventilator-associated pneumonia (Niël-Weise et al 2007). The causes of ventilator-associated pneumonia are multifactorial (Kollef 2004). However, it is generally agreed that inadequate humidification of artificial airways leads to mucocilliary dysfunction, which results in pooling of secretions that may predispose patients to respiratory infections (Chastre and Fagon 2002, Branson 2007). One theory that seeks to explain the pathogenesis of ventilator-associated pneumonia is the aspiration of contaminated oropharyngeal secretions and fluids such as ventilator tubing condensate (Centers for Disease Control and Prevention (CDC) 2003).

Artificial humidification has a significant role in preventing complications associated with mechanical ventilation (Kollef 2004, Siempos et al 2007). Guidelines clearly advocate that artificial humidification is an essential component of caring for mechanically ventilated patients, and it is one of seven identified high impact interventions (DH2007). There is little consensus in the literature regarding which method of humidification is associated with the lowest occurrence of ventilator-associated pneumonia. Some guidelines on the prevention of ventilator-associated pneumonia do not recommend the use of either heat and moisture exchangers or heated humidification over other methods (CDC 2003, NICE 2008), while others clearly advocate the use of heat and moisture exchangers or heated humidification for the humidification of artificial airways (Lorente et al 2006, Branson 2007). Many randomised controlled studies have been conducted to assess which method of humidification is associated with the lowest

\section{BOX 1}

\section{Components of the ventilator care bundle}

- Elevation of the head end of the bed to $30-45^{\circ}$.

- Sedation holding (regularly stopping sedation).

- Deep vein thrombosis prophylaxis.

- Gastric ulcer prophylaxis.

- Appropriate humidification of inspired gas.

- Tube management.

- Secretion removal by suctioning.

- Routine oral hygiene.

(DH 2007) 
occurrence of ventilator-associated pneumonia. Although studies favour the use of heat and moisture exchangers (Memish et al 2001, Kola et al 2005), their effect on lowering the occurrence of ventilator-associated pneumonia was not consistent nor clinically significant when comparing them with the use of heated humidification (Siempos et al 2007).

\section{Methods of artificial humidification}

Artificial humidification can be either active or passive (Poolacherla and Nickells 2006). Active humidification is achieved using heated water humidifiers in which gases pass across or over a heated water bath. Passive humidification is achieved with heat and moisture exchange filters attached to the ventilator circuit. Heat and moisture exchange filters mimic the function of the upper airways by trapping, heating and humidifying gas from the patient's exhaled gas within the filter, returning heat and humidity to the inspired gas on a subsequent inhalation (Lacherade et al 2005). Heat and moisture exchangers are further classified as hydrophobic heat and moisture exchangers, possessing a bacterial filtration property, or hygroscopic heat and moisture exchangers, which have a humidification property (Niël-Weise et al 2007). Many heat and moisture exchangers incorporate paper or polypropylene materials impregnated with a hygroscopic chemical, such as calcium or lithium chloride (Poolacherla and Nickells 2006).

Heated humidification This technique was traditionally used as the primary means of providing artificial humidification (Kollef et al 1998). Heated humidification generally consists of a heating source, water chamber or humidification chamber, temperature control unit and a gas/liquid interface (Figure 1) (Poolacherla and Nickells 2006). In this method, the water in a humidification chamber is heated up sufficiently by the heating source to produce water vapour. As the gas is passed through the chamber, it collects the water vapour before reaching the patient's airway. The humidification chamber is usually placed on the top plate of the heating source/humidifier. It has an inlet that receives medical gas and an outlet that delivers the gas to the patient.

The water level in the humidification chamber can be maintained manually or by using an automatic feed system with an integrated float valve inside the water chamber, which regulates and maintains a constant water level. Manual methods are more likely to lead to reservoir contamination and overfilling, while automatic feed systems eliminate these risks and are used more commonly in many intensive care units (ICUs). A control unit regulates the temperature

\section{FIGURE 1}

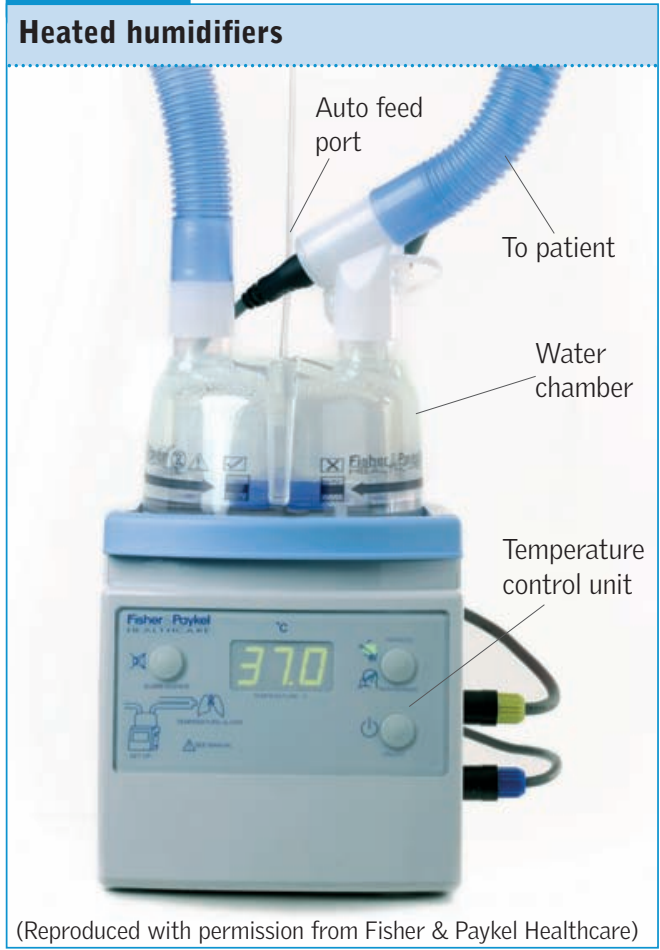

of the gas that flows through the ventilator circuit, with an inspired gas temperature of $33 \pm 2^{\circ} \mathrm{C}$ being set to provide a minimum of $30 \mathrm{mgH}_{2} \mathrm{O} / \mathrm{L}$ absolute humidity (Lemin 2009). A heated humidification system can also be used with or without a heated wire breathing circuit (Lemin 2009). It should be noted that, as the humidified gas passes through the breathing circuit, it cools and condenses, causing water to collect within the inlet limb of the circuit. To compensate for this, the gas in the humidifier can be heated to above $37^{\circ} \mathrm{C}$; however, in certain circumstances this may increase the risk of thermal injury to the patient, for example when using a breathing circuit without a heated wire. By introducing a heated wire into the breathing circuit the need to overheat the gas in the water chamber is eliminated and there is also a reduction in the formation of condensate in the circuit. The purpose of the heated wire in the circuit is to maintain or raise the gas temperature at or above the dew point (the point at which water condenses), hence eliminating water condensation (Lellouche et al 2004). Heated wire breathing circuits may have either a dual limb or single limb circuit. The insulated resistance heating wire runs the full length of the inspiratory and expiratory circuit limbs (Lellouche et al 2004).

\section{Advantages and disadvantages Heated}

humidification has demonstrated better gas humidification than heat and moisture exchangers, although there is no evidence to prove a better clinical outcome (Lellouche et al 2004). A common disadvantage attributed to heated 


\section{art \& science respiratory focus}

humidification is that it increases the risk of condensation and hence condensate in the breathing circuits (Siempos et al 2007), thereby increasing the risk of bacterial colonisation within the circuit (Thomachot et al 1998). Using a heated wire breathing circuit with heated humidification may reduce the formation of condensate (Niël-Weise et al 2007), but there have been no proven advantages compared with the use of non-heated-wire circuits (Branson 2005). Heated humidification does have other disadvantages including high maintenance costs, increased workload for nurses and the risk of endotracheal or tracheostomy tube occlusion caused by incorrect temperature settings (Kollef et al 1998). Other disadvantages include risks such as electrical hazards, over or underhydration of gases and injury such as scalds or burns to healthcare personnel (Poolacherla and Nickells 2006).

Heat and moisture exchangers These devices (Figure 2) are used in many intensive care settings (Niël-Weise et al 2007). The heat and moisture exchanger is usually attached between the catheter mount secured to the patient's endotracheal tube and the ' $Y$ ' connection of the ventilator tubing. Many heat and moisture exchangers provide a moisture output of $22-34 \mathrm{mg} \mathrm{H}_{2} \mathrm{O} / \mathrm{L}$ (Lellouche et al 2004). Mechanically ventilated patients with normal secretions may only require an absolute humidity of $26 \mathrm{mg} \mathrm{H}_{2} \mathrm{O} / \mathrm{L}$ to maintain mucocilliary function (Lorente et al 2006). However, moisture output changes depending on certain factors such as tidal volume, inspiratory time, respiratory rate and temperature (Inui et al 2006). Heat and moisture exchangers are frequently used when a short period (usually less than three days) of mechanical ventilation is anticipated and there is no standard protocol on when to change heat and moisture exchangers.

\section{FIGURE 2}

\section{Active heat and moisture exchanger for heated humidification}

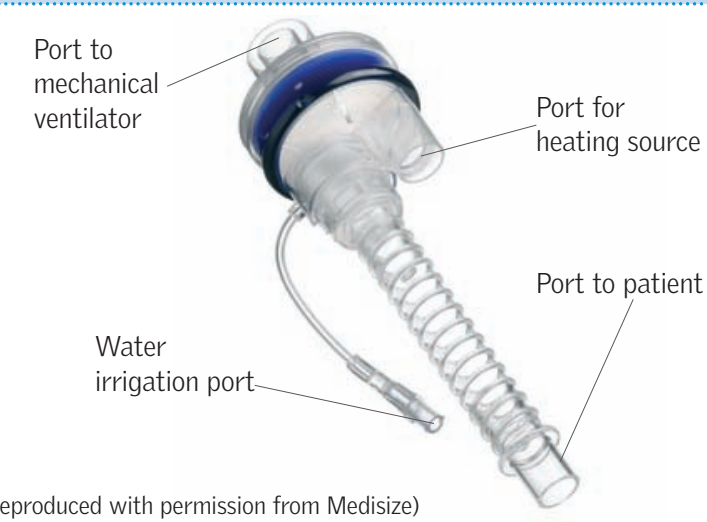

Some studies recommend that heat and moisture exchangers can be used safely for three days (Davis et al 2000), while others recommend changing them after seven days (Dodek et al 2004). However, guidelines on the prevention of hospital-acquired pneumonia suggest that heat and moisture exchangers should not be changed routinely and advise that practitioners should seek guidance from the manufacturers on optimal use and replacement times (Masterton et al 2008).

A new version of the heat and moisture exchanger has been developed, which is known as an active heat and moisture exchanger or heat and moisture exchanger booster (Figure 2). This consists of a heat and moisture exchanger, water infusing system and heating element. It functions in a similar way to traditional heated humidification when the heating element and water system are activated. Many ICUs are starting to use these devices, replacing more traditional heated humidification.

Advantages and disadvantages Many authors support the use of heat and moisture exchangers to provide humidification (Kollef et al 1998, Kola et al 2005). Kollef and colleagues (1998) concluded that heat and moisture exchangers are safe and more cost effective than heated humidification. Heat and moisture exchangers also avoid condensation of liquid in the ventilator circuit and reduce the frequency of ventilator circuit changes (Lorente et al 2004). Other advantages associated with heat and moisture exchangers are reduced nursing workload, reduced financial cost and better safety (Memish et al 2001). Heat and moisture exchange is also the most commonly preferred method of humidification when transferring critically ill patients between departments and other units. Heat and moisture exchangers are small, easy to set up and carry, and eliminate the need for an electric current, whereas heated humidifiers are heavy and require an electric current to function.

The use of heat and moisture exchangers is contraindicated in certain circumstances, for example in patients with bronchopleural fistula or when the expired tidal volume is less than $70 \%$ of the delivered tidal volume, the patient's body temperature is below $32^{\circ} \mathrm{C}$ and when high minute volumes (the amount of air breathed in and out in one minute) are present (Lemin 2009). Heat and moisture exchangers are associated with an increased risk of airway occlusion (Goldsmith and Shannon 2009) and tube dislodgement (Lawes 2003, Poolacherla and Nickells 2006). Using heat and moisture exchangers can also potentially increase deadspace (the volume of gas that does not participate in gas exchange) and airway resistance thereby increasing the work of breathing for the patient (Goldsmith and Shannon 2009). Finally, these devices are 
not recommended for use in patients who produce tenacious and/or copious secretions or who have haemoptysis (Lawes 2003, Lemin 2009).

\section{Nursing implications}

Critical care nurses should ensure that patients who are artificially ventilated receive an appropriate method of humidification according to their individual needs. A thorough clinical assessment should be undertaken to identify which method of humidification is most effective for each patient. Issues such as anticipated duration of ventilation, characteristics of any respiratory secretions the patient produces, contraindications and the cost of using one particular method of humidification over another should be considered. A multidisciplinary approach is essential and patient needs and safety are paramount.

Nurses should ensure that they check humidification devices as part of their safety checks during each shift. These checks should be documented in the nursing records. Incompatible humidification devices may pose a danger to patients and staff (Medicines and Healthcare products Regulatory Agency (MHRA) 2007) and it is recommended that personnel should avoid using a breathing circuit that is not designed for heated humidification. Such use might result in over or underheating or possible thermal injury to the patient's airway. Under no circumstances should a heated wire breathing circuit be covered with bed linen, towels or surgical drapes since this may result in melting of the breathing circuit (MHRA 2007) and is a fire hazard.

Damaged humidifiers and wires should be sent for immediate repair according to the manufacturer's instructions and local policy. Care should be taken to avoid accidental drainage of condensate into the patient's airway when repositioning the patient. Particular attention should be given to heat and moisture exchangers to ensure that they do not become blocked with secretions or blood since this may increase resistance, impede gas flow and affect efficacy in proving adequate humidity (Jaber et al 2004). If there are any signs of contamination, such as visible secretions (sputum or blood) and water condensate, the practitioner should replace the filter immediately. Although routine changing of heat and moisture exchangers is not recommended, they should be changed according to the manufacturer's recommendations or when clinically warranted (Masterton et al 2008) and in line with local infection control policy.

In clinical practice, the ventilator circuit is frequently disconnected for the delivery of nebulised solutions such as $0.9 \%$ sodium chloride or bronchodilator medication, and this may increase circuit contamination. In such circumstances, a metered dose inhaler adaptor can be placed between the heat and moisture exchanger and the catheter mount to enable the administration of metered dose inhalers without disconnecting the circuit. The patient's sputum characteristics should be assessed at each suction procedure. If the secretions become thick and copious then heated humidification should be considered (The Intensive Care Society 2008), since it improves secretion management (Lawes 2003, Lemin 2009) and eliminates the need to break the circuit for frequent administration of nebulisers to maintain tube patency. Many clinical areas now use heated wire breathing circuits with metered dose inhaler adapters. There are also new versions of closed suction systems available that have an additional metered dose inhaler port. This enables metered dose inhalers to be administered without having to break the ventilator circuit.

Disposal of heat and moisture exchangers and heated wire breathing circuits should be carried out according to local infection control policy and the manufacturer's recommendations. Humidification chambers usually become hot soon after use and so careful attention is needed when disposing of them to avoid the risk of fire and/or scalding the practitioner. Heater wires and temperature probes are not disposable and should be cleaned and retained for future use as per local policy. Multidisciplinary team members should be made aware of the non-disposable nature of this equipment since replacement necessitated by inadvertent disposal increases the cost of using such systems. Team members should be aware of the range of humidification devices available in their clinical area and have a clear understanding of how to use them. Staff training should be provided as soon as possible, especially when using new products, to prevent any untoward events . Clear and accurate documentation is vital and should include any issues that may arise in the use of a particular method of humidification. It is also important to seek advice from experts when required.

\section{Conclusion}

Artificial humidification of inspired respiratory gases is important and can prevent a number of complications associated with mechanical ventilation. Several authors believe that higher levels of airway humidity $\left(44 \mathrm{mg} \mathrm{H}_{2} \mathrm{O} / \mathrm{L}\right)$ can enable maximal mucocilliary clearance which can only be given with heated humidification (Williams et al 1996, Lorente et al 2006). In contrast, others believe that gas containing around $26 \mathrm{mg} \mathrm{H}_{2} \mathrm{O} / \mathrm{L}$ is appropriate in most cases, and heat and moisture exchangers can provide this level of humidification 
art \&o science respiratory focus

(Lellouche et al 2004, Lorente et al 2006). However, a multidisciplinary approach should be adopted when selecting humidification devices and decisions should be based on factors such as the patient's clinical needs, safety, cost effectiveness, impact on workload and reduction of risks associated with condensate formation NS

\section{References}

Bersten AD, Soni N (2009)

Oh's Intensive Care Manual. Sixth edition. Butterworth Heinemann Elsevier, Philadelphia PA.

Branson RD (2005) The ventilator circuit and ventilator-associated pneumonia. Respiratory Care. 50, 6, 774-787.

Branson RD (2007) Secretion management in the mechanically ventilated patient. Respiratory Care. 52, 10, 1328-1347.

Centers for Disease Control and Prevention (2003) Guidelines for Preventing Health-Care-Associated Pneumonia, 2003: Recommendations of CDC and the Healthcare Infection Control Practices Advisory

Committee. www.cdc.gov/mmwr/ preview/mmwrhtml/rr5303al.htm (Last accessed: October 6 2010.)

Chastre J, Fagon JY (2002)

Ventilator-associated pneumonia. American Journal of Respiratory and Critical Care Medicine. 165, 7, 867-903.

Davis K Jr, Evans SL, Campbell RS et $\boldsymbol{a l}$ (2000) Prolonged use of heat and moisture exchangers does not affect device efficiency or frequency rate of nosocomial pneumonia. Critical Care Medicine. 28, 5, 1412-1418.

Department of Health (2007) Saving Lives: Reducing Infection, Delivering Clean and Safe Care. High Impact Intervention No 5 - Care Bundle for Ventilated Patients (or Tracheostomy where Appropriate). www.clean-safe-care.nhs.uk/ toolfiles/25_SL_HII_5_v2.pdf (Last accessed: October 6 2010.)

\section{Dodek P, Keenan S, Cook D et al} (2004) Evidence-based clinical practice guideline for the prevention of ventilator-associated pneumonia. Annals of Internal Medicine. 141, 4, 305-313.

Fulbrook P, Mooney S (2003)

Care bundles in critical care:

a practical approach to evidence-based practice. Nursing in Critical Care. 8, 6, 249-255.

Goldsmith A, Shannon A (2009) Humidification devices. Anaesthesia and Intensive Care Medicine. 10, 10, 465-467.

\section{Inui D, Oto J, Nishimura M}

(2006) Effect of heat and moisture exchanger (HME) positioning on inspiratory gas humidification. $B M C$ Pulmonary Medicine. 6, 19, 1-5.

Jaber S, Pigeot J, Fodil R et al (2004) Long-term effects of different humidification systems on endotracheal tube patency: evaluation by the acoustic reflection method. Anesthesiology. 100, 4 782-788.

Kola A, Eckmanns T, Gastmeier P (2005) Efficacy of heat and moisture exchangers in preventing ventilator-associated pneumonia: meta-analysis of randomized controlled trials. Intensive Care Medicine. 31, 1, 5-11.

Kollef MH (2004) Prevention of hospital-associated pneumonia and ventilator-associated pneumonia. Critical Care Medicine. 32, 6, 1396-1405.

\section{Kollef MH, Shapiro SD, Boyd V} et $\boldsymbol{a l}$ (1998) A randomized clinical trial comparing an extended-use hygroscopic condenser humidifier with heated-water humidification in mechanically ventilated patients. Chest. 113, 3, 759-767.

\section{Lacherade JC, Auburtin M,}

Cerf C et al (2005) Impact of humidification systems on ventilator-associated pneumonia: a randomized multicenter trial. American Journal of Respiratory and Critical Care Medicine. 172, 10, 1276-1282.

Lawes EG (2003) Hidden hazards and dangers associated with the use of HME/filters in breathing circuits. Their effect on toxic metabolite production, pulse oximetry and airway resistance. British Journal of Anesthesia. 91, 2, 249-264.

Lellouche F, Taillé S, Maggiore SM et $\boldsymbol{a l}$ (2004) Influence of ambient and ventilator output temperatures on performance of heated-wire humidifiers. American Journal of Respiratory and Critical Care Medicine. 170, 10, 1073-1079.

Lemin M (2009) Clinical perspectives: new developments in mechanical ventilation and humidification. AARC Times. 3, 32-36.

Lorente L, Lecuona M, Galván R, Ramos MJ, Mora ML, Sierra A (2004) Periodically changing ventilator circuits is not necessary to prevent ventilator-associated pneumonia when a heat and moisture exchanger is used. Infection Control and Hospital Epidemiology. 25, 12, 1077-1082.

Lorente L, Lecuona $M$, Jiménez A, Mora ML, Sierra A (2006) Ventilator-associated pneumonia using a heated humidifier or a heat and moisture exchanger: a randomized controlled trial [ISRCTN88724583]. Critical Care. 10, 4, R116.

Masterton RG, Galloway A, French G et al (2008) Guidelines for the management of hospitalacquired pneumonia in the UK: report of the working party on hospital-acquired pneumonia of the British Society for Antimicrobial Chemotherapy. Journal of Antimicrobial Chemotherapy. $62,1,5-34$

Medicines and Healthcare products Regulatory Agency (2007) One Liners Issue 49 - April 2007. www.mhra.gov.uk/ publications/Safetyguidance/ oneliners/CON2031102 (Last accessed: October 6 2010.)

Memish ZA, Oni GA, Djazmati W, Cunningham G, Mah MW (2001) A randomized clinical trial to compare the effects of a heat and moisture exchanger with a heated humidifying system on the occurrence rate of ventilatorassociated pneumonia. American Journal of Infection Control. 29, 5 , 301-305.

Morán I, Bellapart J, Vari A, Mancebo J (2006) Heat and moisture exchangers and heated humidifiers in acute lung injury/acute respiratory distress syndrome patients. Effects on respiratory mechanics and gas exchange. Intensive Care Medicine. $32,4,524-531$.

National Institute for Health and Clinical Excellence (2008)
Technical Patient Safety Solutions for Prevention of VentilatorAssociated Pneumonia in Adults. www.nice.org.uk/patientsafety/ index.jsp?action $=$ pilot $\& 0=12053$ (Last accessed: October 6 2010.)

Niël-Weise BS, Wille JC, van den Broek PJ (2007) Humidification policies for mechanically ventilated intensive care patients and prevention of ventilator-associated pneumonia: a systemic review of randomized controlled trials. Journal of Hospital Infection. 65, 4, 285-291.

Poolacherla R, Nickells J (2006) Humidification devices. Anaesthesia and Intensive Care Medicine. 7, 10, 351-353.

Ricard JD (2007) Gold standard for humidification: heat and moisture exchangers, heated humidifiers, or both? Critical Care Medicine. 35, 12, 2875-2876.

Ryan SN, Rankin N, Meyer E, Williams R (2002) Energy balance in the intubated human airway is an indicator of optimal gas conditioning. Critical Care Medicine. $30,2,355-361$.

Siempos II, Vardakas KZ, Kopterides P, Falagas ME (2007) Impact of passive humidification on clinical outcomes of mechanically ventilated patients: a meta-analysis of randomized controlled trials. Critical Care Medicine. 35, 12, 2843-2851.

The Intensive Care Society (2008) Standards for the Care of Adult Patients with a Temporary Tracheostomy. London, ICS.

Thomachot L, Viviand $X$, Arnaud S, Boisson C, Martin CD (1998) Comparing two heat and moisture exchangers, one hydrophobic and one hygroscopic, on humidifying efficacy and the rate of nosocomial pneumonia. Chest. $114,5,1383-1389$.

Williams R, Rankin N, Smith T, Galler D, Seakins P (1996) Relationship between the humidity and temperature of inspired gas and the function of the airway mucosa. Critical Care Medicine. 24, 11, 1920-1929. 